\title{
Memoria hegemónica y memoria social. Tensiones y desafíos pedagógicos en torno al pasado reciente en Chile
}

Hegemonic Memory and Social Memory. Tautness and Pedagogical Challenges About Recent Past in Chile

Memória hegemônica e memória social. Tensões e desafios pedagógicos em relação ao passado recente no Chile

\section{Graciela Alejandra Rubio* (ID orcid.org/0000-0002-4849-835X}

\section{Artículo de investigación}

Revista Colombiana de Educación, N. 71. Segundo semestre de 2016, Bogotá, Colombia.

Para citar: Rubio, G. (2016). Memoria hegemónica y memoria social. Tensiones y desafíos pedagógicos en torno al pasado reciente en Chile. Revista Colombiana de Educación, (71), 109-135.

Recibido: 15/02/16

Evaluado: 11/04/16

* Es doctora en Educación por la Universidad de Granada, magíster en Historia de Chile por la Universidad de Chile, licenciada en Historia por la Universidad Católica de Valparaíso y profesora de Estado en Historia y Geografía por la misma casa de estudios. Se ha desempeñado como investigadora de la CEAAL y como académica de la UMCE. Actualmente es profesora invitada en el magíster en Enseñanza de las Ciencias Sociales de la Universidad del Biobío y académica de programas de magíster y doctorado en Educación. Correo electrónico: Graciela.rubio@uv.cl 


\title{
Resumen
}

El articulo analiza las narrativas de memoria y perspectivas sobre la historia reciente presentes en el currículum escolar de historia y ciencias sociales y en dos contextos de trabajo de memoria en la sociedad civil. La memoria promovida en cada escenario evidencia las representaciones políticas del pasado reciente, las distancias entre la memoria hegemónica y las memorias sociales y las tensiones para la elaboración del recuerdo sobre el pasado reciente en las nuevas generaciones. Se discuten las connotaciones éticas y políticas presentes en el recuerdo elaborado y se exponen los desafíos pedagógicos y unas orientaciones que deben atenderse para la formación de una ciudadanía memorial responsable de su pasado heredado y de su futuro en construcción.

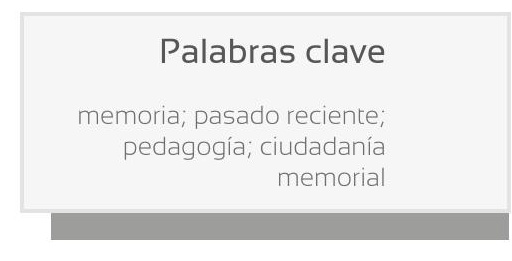

\section{Keywords}

memory; recent past memorial pedagogy; citizenship

\begin{abstract}
The article analyzes the narratives of memory and perspective on recent history present in the school currículum of history and social sciences and in two contexts of memory work in civil society. The memory in each scenario promoted political representations evidence of the recent past, the distances between the hegemonic memory and social memories and tensions for the elaboration of memories of the recent past in the new generations. ethical and political connotations present in the memory are discussed and elaborated pedagogical challenges and orientations that must be addressed for the formation of a memorial responsible for its inherited past and future citizens are exposed under construction.
\end{abstract}

\section{Resumo}

O artigo analisa as narrativas de memórias y perspectivas sobre a história recente presentes no currículo escolar da História e Ciências Sociais e em dois contex tos de trabalho de memória na sociedade civil. A memória promovida em cada ambiente evidência as representações políticas do passado recente, as distâncias entre a hegemonia e as memórias sociais e as tensões para a elaboração do acordo sobre o passado recente nas novas gerações. As conotações éticas e políticas presentes no acordo são discutidas e se expõem os desafios pedagógicos e umas orientações que tem que atender-se para a formação duma cidadania memoriai responsável de sue passado herdado e de seu futuro em construção.

\section{Palavras chave}

memória; passado recente; pedagogia; cidadania memoriai

N. ${ }^{\circ} 71$ 
$\mathrm{E}$ siguiente texto forma parte de un programa de investigación sobre memoria, pasado reciente y pedagogía de la memoria sobre el caso chileno ${ }^{1}$. Desde una aproximación crítica de la memoria y desde una hermenéutica de la historia, se reconoce el pasado reciente como un campo abierto de disputa que reviste implicancias políticas y éticas, así como un recurso histórico y pedagógico que requiere vincular la memoria, la historia y los derechos humanos para la formación de las ciudadanías actuales.

\section{El campo problemático del pasado reciente y la disputa política por el recuerdo}

Los estudios sobre el pasado reciente ${ }^{2}$ se han venido consolidado a partir de una convergencia de intereses investigativos, políticos, sociales y recientemente pedagógicos. Tanto movimientos ciudadanos como las aperturas teóricas y críticas de las ciencias sociales, han establecido el recuerdo y las memorias silenciadas por la historia como objeto de conocimiento y fuente de identidad política (Jelin, 2003). Las prácticas de represión y exterminio, el terrorismo de estado, las transiciones a la democracia, junto a los procesos acelerados de modernización vividos en las últimas décadas, han Ilevado a integrar enfoques reflexivos sobre los efectos sociales y subjetivos olvidados por la historia y han validado la memoria como un dispositivo problematizador del presente que puede agenciar procesos emancipadores. La historia reciente ha abierto una tensión epistemológica entre quienes defienden la exclusividad de la investigación historiográfica para la generación del conocimiento (Cruz, 2015³: Aróstegui, 2006) y quienes reconociendo los contextos complejos de transformación y aperturas de la experiencia temporal, de la práctica historiográfica y de los regímenes

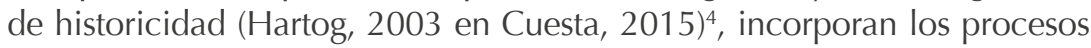
subjetivos y políticos para sustentar el carácter crítico que puede asumir

1 Se ha abordado; el devenir de las políticas de la memoria sobre el pasado reciente derivado de la discusión pública de los informes de verdad Rettig y Valech (1990-2014). La inviabilidad del perdón y la reconciliación como dispositivos para la cohesión social y las bases epistemológicas que vinculan memoria y educación.

2 Usamos Pasado reciente para enfatizar el carácter abierto a discusión de esta categoría temporal. No contradice el de Historia reciente.

3 Cruz, cuestiona el potencial generador de conocimiento de la memoria dado su carácter subjetivo.

4 Los marcos temporales de la modernidad ordenaron la experiencia social del tiempo en las categorías pasado, presente y futuro. La aceleración se hizo parte del marco y los tiempos de globalización la han acrecentado generando efectos negativos para pensar futuro y generar acción. Memoria y olvido. Dos categorías pendientes de reconsideración. En Seminario," Pensar lo contemporáneo". Facultad de Humanidades, Instituto de Historia Universidad de Valparaíso. Octubre,2015. Apuntes. 
la memoria ${ }^{5}$. (Rubio, 2013a, Cuesta, 2011, Osorio y Rubio, 2006). Desde esta perspectiva, ante el pasado reciente no es posible sostener una "ingenuidad epistemológica" sobre la correspondencia univoca entre narración histórica y hecho narrado, más bien, conviene abrir la discusión sobre la incidencia de contextos y subjetividades en la construcción y circulación social del recuerdo, enmarcando la discusión entre conocimiento, subjetividad y política. Lechner y Guell (2006) ya habían afirmado, cómo la memoria configurada intersubjetivamente, actúa como puente entre un tiempo abstracto común (pasado, presente y futuro) generado en la modernidad y el ámbito cotidiano de la vida social en la producción social del tiempo y del orden.

El pasado reciente evidencia la continuidad entre la narración y la experiencia temporal, tensionando la relación entre el discurso histórico, la memoria social y el contexto sociopolítico en que se produce el recuerdo, discutiendo sobre el valor de la verdad, la neutralidad valorativa del hecho y el carácter ético y político del relato (Mudrovic, 2005). Desde esta perspectiva, conviene explicitar la relación dialógica entre presente y pasado y cómo el investigador y las memorias sociales participan de un contexto mediado por "intereses prácticos" (Ricoeur, 2004) que contextualizan los "discursos sobre el pasado reciente" como una producción social del presente que exige pensar el poder implícito en "los usos del pasado". En la esfera pública, se ha discutido sobre la consideración política y ética del presente y sobre las proyecciones de futuro-que reviste toda modalidad de memoria (Ricoeur, 2004; Arendt, 2005), sobre la función asumida por las políticas de la memoria (RuizTorres, 20076: Lefranc, 2004, 2003) en contextos transicionales de violencia y de consolidación de la democracia (Elster, 2006) sobre los vínculos entre estas y los registros analíticos del tiempo largo de la historia, para la constitución de un entramado político y del Estado (Collins y Joignant, 2013) y sobre los usos políticos del pasado y vestigios de historización presentes en los Informes de Verdad (Jaramillo, 2009, Rubio, 2010).

Diversas agencias políticas promotoras del recuerdo (Todorov, 2000) han integrado la designaciones, "memoria viva", "el valor del testigo" y "el deber de la memoria" las que si bien se han originado en la memoria

5 La visión crítica, también cuestiona los usos del pasado y la forma de olvido que puede instalar.

6 Los movimientos memoriales se han identificado con la designación "Memoria histórica" dado el carácter de ese pasado y su vínculo con el presente, como una crítica a la historia y a las políticas de olvido. Los historiadores suelen oponer la historia, a la memoria colectiva e histórica. En el último tiempo, ha sido parte de una agenda política que ha convertido la memoria en un imperativo oficial. Ver las particularidades de los casos de Guatemala, Colombia y España. En estos tres países se ha incorporado el sintagma "memoria histórica" en sus agendas públicas por vía legislativa como en el caso español, por vía de un acuerdo de paz como en Guatemala, o por vía de una narrativa transicional y un marco normativo como en el caso colombiano. 
del Holocausto (Reyes Mate, 2008; Melich, 2004), se han incorporado en discusiones sobre el pensamiento antifascista, la evocación del pasado como fuente de revitalización de utopías, la apuesta por el fortalecimiento de la política ante una creciente fuerza de olvido y dispersión en sociedades neoliberales, la relación entre el poder y las memorias en las transiciones democráticas y con la justicia e identidad de comunidades silenciadas, entre otras. La reflexión sobre las memorias colectivas, ha discutido sobre su incidencia en la constitución de las identidades políticas (Pollak,2006) y el potencial reivindicativo que puede desplegar su "trabajo" (Jelin, 2002). La integración de la memoria en el contexto educativo, ha sido más reciente y ha enfatizado, su vínculo con las ciudadanías, en el marco de una "economía política del recuerdo" (Cuesta, 2011), las bases de las pedagogías de la memoria (Bárcena,2011) para contribuir a la formación de una "ciudadanía memorial" (Osorio y Rubio, 2014, Rubio, 2013a) y la validación la memoria como dispositivo para la formación politica en "ecologías violentas" (Vélez y Herrera,2014).

\section{Pasado reciente y memoria. El devenir de las tensiones y dilemas de su representación social}

Desde 1990 los gobiernos democráticos para consolidar una transición pactada y regulada por la constitución de $1980^{7}$ decidieron afianzar la democracia establecida abriendo campo de maniobra y circunscribiendo lo posible a los acuerdos (Lechner y Guell,2006). Para ello, se elaboró una política de la memoria del pasado reciente sustentada en principios oligárquicos de lo público que integró el perdón y la reconciliación como dispositivos reguladores de la cohesión social, en donde el discurso político ha tenido un rol determinante en la definición de una memoria hegemónica (Rubio, 2013). El pasado reciente fue esquivado, imaginando el futuro sin una memoria social integrada. "Dar tiempo al tiempo", "mirar a futuro" o, "Chile no quiere volver al pasado", se instalarían como argumentos ante el conflicto emergente, de cara a lo que se llamó la fragilidad de "un nosotros" (Lechner, 1999). Al respecto, Garretón (2003) ha destacado la incidencia que tiene en el futuro de un país, el modo en que una sociedad en tanto comunidad histórico moral, enfrenta y resuelve los problemas de su pasado ${ }^{8}$. La "ausencia de un nosotros", la desvinculación y cierre del

7 El gobierno de Aylwin se definió en un marco político legal fijado por la constitución de 1980; una economía capitalista de mercado en expansión; la permanencia de Pinochet en le escena política (Comandante en jefe y senador vitalicio) y una distribución bipolar estable de las fuerzas políticas. En este de transición, el gobierno se propuso afianzar el régimen democrático, reformar la economía vinculando crecimiento con equidad y juzgar las violaciones de derechos humanos.

8 Hitos históricos compartidos y relevantes del pasado reciente para ser discutidos según Garretón son: la unidad popular y la crisis del proyecto nacional, el golpe militar y la dictadura, el plebiscito de 1988 y la redemocratización. 
pasado y el aislamiento de las memorias, ha venido consolidando subjetividades ${ }^{9}$ que evidencian una débil integración del pasado reciente para pensar futuro.

La relación disociada con el pasado reciente ha sido reforzada por un imaginario histórico social construido en democracia a partir de una retracción relativa del estado ante el mercado, en el cual la imagen y la cultura globalizada habrían debilitado los imaginarios colectivos, emergiendo versiones individualizadas del consumo, la globalización y el trabajo. Los gobiernos democráticos habrían enfatizado, el carácter funcional de la política, obviando, los miedos y las emociones, configurando una identidad nacional vaciada de experiencia social (Informe PNUD, 2002). Lo que, unido al histórico imaginario colectivo basado en el "orden", usado para encubrir conflictos políticos y sociales y el miedo al otro (una subjetividad indomable) habrían articulado una visión de la gobernabilidad en la transición basada en el miedo al "caos", asociado a la Unidad Popular y el miedo al "castigo", instalado por la dictadura." Asegurar la gobernabilidad es conjurar el temor al caos y poner límites a lo deseable y lo posible." (Informe PNUD, 2002:59). En la misma línea, desde la historia de las emociones, se ha evidenciado cómo la política del terror aplicada por la dictadura, ha incidido en la generación de un "miedo derivativo hacia la democracia" (Timmermann,2015). Estos imaginarios sociales subyacen en los actuales "tiempos de politización" en los que movimientos ciudadanos han cuestionado la legitimidad del orden establecido, instalando nuevas referencias de discusión y el reconocimiento de las diferencias sociales y culturales como derechos, exigiendo de la clase gobernante una congruencia ética política ${ }^{10}$.

El análisis político de los estudios de opinión realizados entre 1986 y el 2011 evidencia cómo la experiencia dictatorial chilena caracterizada por: una violencia militar inesperada, la concentración del poder de Pinochet $^{11}$, el uso de mecanismos de cooptación y de preservación basados en una amplia distancia entre el régimen y la oposición junto con el uso de un lenguaje belicoso, más extremo que el empleado por otros dictadores

9 El Informe PNUD (2014) entiende por subjetividad el espacio y el proceso en que los individuos construyen una imagen de sí, de los otros y del mundo en el contexto de sus experiencias sociales. Este ámbito está formado por sus emociones, imágenes, percepciones, deseos, motivaciones y evaluaciones, entre otros elementos.

10 Las nuevas ciudadanías, se caracterizan por una débil participación, una mirada individualizada de lo público y una alta desconfianza de la clase política. (Informe PNUD, 2015)

11 Pinochet se valió de diversas estrategias de legitimación; legitimidad legal como Comandante en Jefe del Ejército y legitimidad electoral basada en la pretensión de contar con el apoyo del país. (elecciones no competitivas en 1978 y en 1980). Si bien no tuvo éxito en el tercer intento (plebiscito de 1988), fue Presidente de la Republica, Presidente de la Junta militar y Comandante en jefe del Ejército y líder de la coalición gobernante. 
de la época, habrían potenciado una "separación amigo-enemigo" en la sociedad(Hunneus e Ibarra, 2013).

Se considera que la presencia de Pinochet en los primeros 8 años de la democracia apoyado por la derecha chilena, líderes empresariales y algunos segmentos sociales habría tenido un profundo efecto en la cultura cívica dividiendo al país y habría generado una falta de entusiasmo por la democracia $^{12}$. Del mismo modo, la intensidad de la violencia ha incidido en la fuerza de la memoria sobre la violencia dictatorial y el rechazo a la violación de Derechos Humanos, pese a que desde el 2011 la vitalidad de la memoria del régimen militar se ha debilitado entre los más jóvenes.

Los estudios sobre memoria colectiva en relación al pasado reciente (Carvacho et al, 2013) evidencian la persistencia de una cultura política transgeneracional ${ }^{13}$ que reconoce los hechos del pasado histórico traumático del golpe de estado, la dictadura y la transición, pero que presenta una alta ideologización que determina las transmisiones intergeneracionales de memoria y su interpretación sobre las causas y consecuencias del golpe militar y de las políticas de reparación y memoria. Del mismo modo, se ha visto que las identidades sociales (nacional y política) de las nuevas generaciones, de acuerdo a su vínculo con el conflicto del pasado reciente (víctima o victimario) se relacionan con la disposición a reparar y perdonar (Carvacho y Manzi, 2013) $)^{14}$. Y, dado que las identidades políticas son persistentes en Chile, la reducción del conflicto no podría depender del debilitamiento de estas, sino de la activación de la capacidad para comprender la perspectiva que respecto del mismo conflicto tiene la otra parte. Mientras, el trauma psicosocial de la tortura y la prisión ilegitima sigue siendo transmitido y apropiado por las generaciones herederas (nietos) de las víctimas, evidenciando la permanente presencia de la violencia y la fisura social (Faúndez y Cornejo, 2013). Otros estudios de memoria, ciudadanía y pasado reciente realizados en niños y adolescentes entre 13 a 17 años de edad (Opción, 2013) muestran una tendencia al rechazo a la dictadura y una defensa normativa de los DDHH. Sin embargo, el gobierno de la Unidad Popular y el Golpe de Estado de 1973 son abordados desde un marco histórico de bipolaridad y desde la idea de inevitabilidad de la crisis politica y sus efectos. Lo que, asociado a un escaso dominio sobre los hechos históricos relacionados, se traduce en la ausencia de un piso mínimo de argumentos para condenar a la violación de DDHH como

12 El caso chileno contradice las tendencias de la literatura que asocian el aumento del crecimiento económico y una reducción de la pobreza con el aumento explícito de la adhesión a la democracia.

13 Diversos estudios coinciden en que la identidad grupal afecta el juicio de verdad sobre lo que se recuerda y los recuerdos, a su vez, afectan los procesos de categorización grupal.

14 Discrepamos del uso del perdón y la reconciliación en la transición chilena como un modo de restituir la sociedad. 
hecho histórico y la nula relación de la historia reciente con el presente. Estas tendencias plantean desafíos pedagógicos para integrar la memoria como una herramienta crítica para la comprensión del pasado reciente y como recurso para el aprendizaje ciudadano.

\section{Las políticas de la memoria del pasado reciente, los informes de verdad y la memoria hegemónica del currículum de historia y ciencias sociales}

El trayecto de las políticas de la memoria ${ }^{15}$ según Wilde (2013), permite reconocer una primera fase de "erráticas irrupciones de memoria" (19901998) en Chile, en el inicio de la transición marcada por el reconocimiento de la verdad de violación de Derechos Humanos a partir del Informe Rettig (1991), junto con los hallazgos de los cuerpos de los detenidos desaparecidos y la demanda de justicia, tensionada por la presencia de Pinochet en la comandancia en jefe del Ejército y por la participación en el poder de las fuerzas políticas que habían apoyado a la dictadura. El carácter de esta fase, en una democracia "semiautoritaria y protegida" (Wilde) llevó a plantear preguntas simbólicas y morales sobre la relación entre el pasado reciente, la clase política, los militares y empresarios, lo que habría generado una retracción de la democratización. ${ }^{16}$ La segunda fase calificada por el autor como un "tiempo de memoria" (19982010), caracterizada por la agilización de los procesos en tribunales, la convocatoria de la mesa de diálogo (1999-2000), la conmemoración de los 30 años del golpe militar (2003), la declaración ese mismo año, del "Nunca más del Ejercito" y la difusión del Informe Valech (2004), abrieron un nuevo contexto de discusión pública sobre el pasado reciente. La memoria tuvo una influencia excepcional en las políticas públicas en los gobiernos de Ricardo Lagos (2000-2006) ${ }^{17}$ y de Michelle Bachelet

15 Entre algunas de las acciones se encuentran: fijar fechas y días conmemorativos; espacios para la memoria (museos, monumentos, memoriales, parques y rutas de la memoria); creación de instituciones y redes (Comisiones de Verdad, desarrollo de Secretarías o Asesorías especiales; redes entre instituciones; reconocimientos públicos placas conmemorativas; reconocimientos a organizaciones de víctimas; o el quitar reconocimientos que conmemoren circunstancias de las dictaduras; educación, investigación y difusión desarrollo de recursos pedagógicos, concursos para estudiantes, programas de sensibilización, talleres para profesores, políticas educativas, investigaciones encomendadas por el Estado o su financiación);gestión de documentación y archivos (creación de archivos históricos, desclasificación de archivos). Ver Garretón, Francisca, et al, 2011.

16 El ciclo se cerraría con la detención de Pinochet en Londres (1998) que abriría un cuestionamiento a la transición y un incremento de las demandas por justicia en tribunales.

17 A través de la iniciativa "No hay mañana sin ayer" dio curso a procesos de memoria y reparación. El proyecto de creación del Instituto Nacional de Derechos Humanos ingresó al Parlamento el 2005 y fue abierto por Michelle Bachelet en el 2009. 
(2006-2010) $)^{18}$ los que en continuidad abrieron un fuerte activismo ciudadano por la justicia, la responsabilidad del estado ante la prisión ilegitima y la tortura en dictadura y un creciente proceso de apoyo a la memorialización que se cerraría con la apertura del Museo de la Memoria en 2010. Wilde, considera que la reivindicación de la memoria habría marcado el curso de la democratización llevando a la esfera pública cuestiones de índole ética y simbólica fomentando poderosas políticas públicas que se impusieron como iniciativas presidenciales, pese a la presión de sectores pinochetistas por "dar vuelta la página". Desde nuestra perspectiva, la experiencia chilena ha debatido sobre el aporte de la memoria a la verdad (1991-1998) ${ }^{19}$; la recuperación de la memoria republicana para fortalecer el imaginario social común (2003-2004)20; la memoria del dolor y la responsabilidad social ante la política de campo $(2004)^{21}$; la necesidad de preservar la verdad sobre la violación de derechos humanos y la historia reciente ante las nuevas generaciones para evitar su repetición (2009-2010)22 y; la discusión de memoria y sustentabilidad ética de la democracia construida, a 40 años del golpe militar de 1973 (2013-2015)23.

La política de memoria ha mantenido una distancia prudencial ante las iniciativas privadas de memorialización (2006-2015), aportando a su financiación, pero con escasa influencia posterior, lo que ha generado una disparidad expresiva de los espacios de memoria. Los memoriales públicos ${ }^{24}$ se han considerado relevantes, para aliviar la carga del pasado y para promover un diálogo productivo y la participación. Interpelan a la democracia a través de escenarios abiertos de memoria y política

18 El Gobierno de Michelle Bachelet evidenció la mayor expansión de iniciativas de memoria con la sociedad civil. Los memoriales Ilegarían a 160 en 2010 según Wilde y sobre 200 en 2014, según Collins y Hite. (2013).

19 Es una constante que se redefine de acuerdo a los procesos de justicia y de acuerdo a la memoria hegemónica.

20 Con motivo de la Conmemoración de los 30 años del Golpe Militar

21 Término usado para referirse a los espacios de detención, tortura y exterminio utilizados por la dictadura militar. En el caso chileno, se ubicaron a lo largo de todo el país, incluyendo casas habilitadas especialmente para ello, escuelas, comisarías y diversos espacios que trastocaron su uso. También, alude a las estrategias utilizadas por Pinochet para instalar el miedo y la duda como una normalidad de esta política, al aplicarla y luego negarla sistemáticamente a través de los medios de comunicación.

22 La Inauguración del Museo de la Memoria y de los Derechos Humanos, una institución semiprivada financiada por el estado.

23 Desde la conmemoración de los 40 años del Golpe Militar, en el marco de una crisis de la democracia establecida, la memoria social de la opinión pública ha cuestionado la representatividad y calidad ética de los gobernantes como resultante de la transición.

24 Los hay de carácter público y privado; representativos de las víctimas y de los colaboradores; beneficiarios y desposeídos de la Dictadura; de las Fuerzas Armadas y de los violadores de derechos humanos. Los Sitios de Conciencia son memoriales públicos que asumen un compromiso con la democracia mediante programas que estimulan el diálogo sobre temas sociales urgentes del hoy y que dan oportunidades para la participación pública en aquellos temas. 
pudiendo potenciar diversas acciones y capacidades democráticas y problematizar el pasado -el presente y el futuro aportando a la narrativa histórica para la construcción de identidades en las democracias postconflicto (Brett, et al, 2007). Se organizan en torno a la defensa de los derechos humanos cuando son promovidos por la sociedad civil y enfatizan el quiebre político cuando son liderados por el estado. Y plantean desafíos respecto del pasado reciente sobre qué enfatizar; las víctimas o los victimarios, los muertos o los sobrevivientes. $Y$ en la vinculación entre memoria e historia; se tensionan sobre qué enfatizar, la verdad del hecho o, la causa y sobre cómo inscribir narrativamente el fragmento de memoria en la historia (Collins y Hide, 2013).

\section{Los Informes de verdad y la memoria hegemónica}

La Informes de Verdad, Rettig (1991) ${ }^{25}$ y Valech $(2004)^{26}$, han establecido la verdad pública y han definido los marcos históricos e interpretativos sobre el pasado reciente en Chile. El Informe Rettig, aborda el pasado apoyándose en las categorías del perdón, como extensión social de las culpas y restaurador de la democracia, y de reconciliación, como gesto de unidad y cierre de la violación de derechos humanos. Ambas categorías, fundan sus significados en un pensamiento cristiano conservador de reminiscencias coloniales. Su relato histórico centrado en el contexto anterior al golpe (1965-1973) y la dictadura, destaca la causalidad de la violencia, liberando de paso, a los involucrados. El período dictatorial (1973-1990) se presenta a partir de los bandos militares, evidenciando la desaparición de personas como una historia sin nombres, sin acciones pensadas e intenciones explícitas que permitan comprender la trama de eliminación de ciudadanos ${ }^{27}$. A ello se agregan, la defensa de una verdad innombrada, que debe ser aceptada como mandato superior y el "exordio" para atender la verdad de la desaparición de ciudadanos. La expresión de la memoria en el espacio público es bloqueada por la ausencia de voz y cuerpo de las víctimas a las que se pretende restituir su dignidad. En suma, por la imposibilidad de que los detenidos desaparecidos y los muertos recuerden y perdonen.

25 Quedan fuera del Informe las torturas y detenciones arbitrarias. La verdad histórica solo recoge los hechos relacionados con las víctimas desaparecidas entre 1973-1990. La Comisión incluyó como atentados a los derechos humanos no solo los llevados a cabo por agentes del Estado, sino también las acciones subversivas desarrolladas por los opositores el régimen.

26 Su misión fue recoger los testimonios de las víctimas de violación de derechos humanos, en el período 1973-1990. Para el año 2010, se convocó a una reapertura del Informe, aumentando el número de testimoniantes reparados por el Estado. Pese a no presentar una nueva tesis histórica sobre la experiencia vivida, el Museo de la memoria y de los derechos humanos, ha propiciado el contacto con un espacio testimonial público sobre la represión (1973-1990).

27 La violencia se aplicó con mayor fuerza en mujeres, marxistas y analfabetos. 
En el informe prevalece una visión estructurante de la historia reciente (1970-1990) que naturaliza la violencia, como fuerza incontenible que condujo a una guerra civil (Lechner, 2006). Situada en un tiempo largo, formaría parte de un proceso histórico decadentista de fines del siglo xx. La fuerza de la violencia ratificaría el trastrocamiento de "la nación imaginada" (Bengoa, 1996), lo que permite representar la crisis política de 1973 como expresión y aceleración de esa decadencia y a la vez, como causa del golpe de Estado. Definiendo a los ciudadanos como creaturas de Dios (sic), desarrolla la tesis de la violencia inevitable y del caos político institucional y responsabiliza al gobierno de la Unión Popular (UP) de la crisis del Estado y de la violencia dictatorial. Esta tendencia continuaría, al conmemorar los 30 años del golpe militar (2003). El informe no restituye la ciudadanía. Está dedicado a confirmar la muerte y desaparición forzada de más de 2000 chilenos y dar claves sobre su "paradero" para luego recomendar políticas de reparación. No hay cuerpos $^{28}$. El Informe permitirá asentar la política de los acuerdos, sustentada en una verdad sin justicia. No obstante, la realidad se impondría más decididamente, en tanto que no habría arrepentidos y los familiares de las víctimas no perdonarían y, de modo auténtico, exigirían justicia ${ }^{29}$.

El Informe Valech, presenta la verdad de la prisión ilegítima y la tortura. El relato histórico también, sin nombres de responsables, está centrado en la experiencia de la violación de los derechos humanos durante la dictadura (1973-1990) y valida, como fuente de verdad, el testimonio de una experiencia social compartida por las víctimas, que aún están vivas $^{30}$. Releva con ello, a la ciudadanía y su memoria de dolor, como fuente de verdad pública. Redimensiona el recuerdo promoviendo una responsabilidad moral de la sociedad ante la memoria del dolor y del quiebre del cuerpo personal y político. Sin embargo, subordina dicho testimonio a una explicación histórica global, dadas las condiciones de Guerra Fría y los procesos derivados desde mediados del siglo xx, los hechos del pasado reciente acaecieron por fuerzas inmanejables.

La naturalización del curso de la historia se vuelve a recomponer en 2003-2004, esta vez, para conciliar la sociedad reconstruida. El presidente Lagos lo incorporará como fundamento de restitución de la ciudadanía

28 El discurso del ex presidente Aylwin y sus asesores consideraría la nación como una entidad constituida por seres creados por Dios, que, en un trayecto histórico definido por la búsqueda de la salvación, es posible transitar por el martirologio.

29 Aylwin no modificó la Amnistía dictada en 1978, más bien optó por potenciar la verdad en la investigación. El documento está más centrado en el pasado. La relación que el ex presidente estableció entre la amnistía, la verdad parcial y la reparación, sería cuestionada por los hallazgos de osamentas humanas, las querellas que identificaron a colaboradores y torturadores del régimen y a detención de Pinochet en Londres (1998).

30 El testimonio de quienes sufrieron tortura y prisión ilegitima, entre 1973 y 1990 promueve una responsabilización social ante el dolor. 
y de la República ${ }^{31}$, liberando del juicio público a la clase política. La narrativa del Informe, se estructura desde una concepción de estado laico constituido por ciudadanos insertos en un pasado histórico que subordina las decisiones políticas locales a la política internacional. Integra, en un mismo relato el contexto y la causa y de modo desigual, la responsabilidad de las fuerzas armadas, la clase política y la ciudadanía. Nuevamente, la memoria social queda subordinada a una memoria oficial debilitando la visión del pasado como un hecho histórico, reforzando una subjetividad social que no ha podido construir una expresión temporalizada de sí misma (Lechner, 2007). La discusión pública y los Informes de Verdad han enmarcado el pasado reciente de Chile en tres tesis históricas explicativas. La tesis de la crisis republicana explica los hechos de 1973, como una crisis natural de la historia política del siglo $\mathrm{xx}$, en la medida en que esta se abrió a la participación popular; la tesis del determinismo e inevitabilidad de la violencia, una suerte de fuerza natural constitutiva de la sociedad, activada en este caso, por la Unidad Popular, y la tesis de la Guerra fría (2003-2015) explicaría lo vivido como resultado de la fuerza de las ideologías en el mundo bipolar, instalando una desresponsabilización de la clase política local sobre los hechos ${ }^{32}$. (Rubio,2014).

\section{La memoria hegemónica en el currículum escolar de historia y ciencias sociales}

El currículum vigente sustenta la enseñanza del pasado reciente en Chile a partir del análisis político de los hechos históricos y ensambla en un marco historicista del relato las 3 tesis explicativas del golpe de estado de 1973 y de la violación sistemática de los derechos humanos ya mencionadas. Las tesis ordenan el relato histórico secuencialmente, en lógica ascendente y positiva hacia el presente. La tesis de la Guerra Fría, actúa como marco explicativo global de la historia y sus efectos, y las dos primeras (Decadencia de la república y Determinismo histórico), ordenan las coyunturas políticas inmediatas al golpe de estado de 1973. Todas consolidan unas memorias Hegemónicas que orientan una

31 El gobierno de Lagos en pos de recuperar la memoria republicana, pintó de blanco la casa de gobierno ("Blanqueo de la Moneda"), dando otra fisonomía a la construcción gris, bombardeada en 1973. El Presidente, en ritual televisado, reabrió simbólicamente la entrada a la casa de gobierno, por la puerta de Morandé 80 (2003) que antaño utilizara el presidente Salvador Allende, la que había sido clausurada por la dictadura, redefiniendo los símbolos republicanos asociados al liderazgo de Allende.

32 Las dos primeras se desarrollan en el pensamiento conservador antes de 1990 y hasta 2003. La tesis de la guerra fría, da una "explicación histórica" -la guerra en un contexto mundial- que permite la convivencia de las tesis anteriores en un presente estable. Su plasticidad permitió integrar el "Nunca más" del General Juan Emilio Cheyre (declaración del Comandante en Jefe del Ejército que presentaría públicamente su participación histórica en la violación de los Derechos Humanos) y el dolor social de los testimonios de quienes fueron torturados y apresados ilegítimamente durante la dictadura. 
pedagogía de sentido de la experiencia social que evade la reflexión de los hechos históricos, asume tácitamente la imposición del perdón y promueve una memoria ingenua que no se apropia de la existencia histórica de la violación de derechos humanos como expresiones de la Política de campo instalada en la Dictadura Militar (1973-1990). El currículum elaborado en contextos de democratización y modernización (1990) debía consolidar los procesos de reforma neoliberal globalizados y los propósitos de crecimiento con equidad. El pasado reciente debía incorporarse desde un marco explicativo que fortaleciera el consenso entre los jóvenes y las prescripciones políticas de los gobiernos democráticos. El Manifiesto de Historiadores (1998), denunció las falacias y omisiones de las "verdades históricas" acuñadas, al reducir el proceso histórico al período en que es posible justificar el golpe, silenciar los procesos históricos estructurales y la correspondiente responsabilidad oligárquica acumulada, así como atribuir la crisis de la política de 1973, a la implementación de las reformas económicas y sociales y asignar una visión moralista a la intervención militar (Reyes,2004). A estas formas discursivas se agregarían el 2003, en la conmemoración de los 30 años del golpe militar, la recuperación del liderazgo político de Allende en la opinión pública y los rituales elaborados por el gobierno de Ricardo Lagos que integrarían el pasado reciente como una política de estado para fortalecer la memoria republicana de la Historia del siglo xx. (Rubio, 2013b).

Los programas de Historia y Ciencias Sociales sugieren que el pasado reciente se vincule directamente con la valoración de la democracia, la aceptación del pluralismo político y cultural y el respeto de los derechos humanos. Refuerzan el concepto de crisis de la república y la necesidad de "aprender" sobre los cambios económicos e institucionales impulsados por la dictadura (Mineduc, 2013; 2009; 1998) delegando al docente la transmisión de la compleja memoria social de la política de campo. La valoración de la lucha por los derechos humanos y la recuperación de la democracia, se exponen detalladamente enfatizando las políticas públicas trazadas por los gobiernos de la Concertación desde 1990, además de la "democratización" y el "Nunca Más" del Ejército (2003). El currículo no habilita la transmisión de una memoria responsable que integre los derechos humanos como un principio de comprensión de la experiencia social del pasado reciente y no potencia la discusión de la violación de derechos como hechos históricos reconocidos y abordables. Las nuevas definiciones de los programas, ajustes (2009) y bases curriculares (2012), comparten el orden historicista de la interpretación histórica; el uso de la Guerra Fría y del quiebre republicano como tesis explicativas, la apuesta por el reconocimiento de la diversidad de interpretaciones históricas sobre el siglo xx y el deber de la formación ciudadana. Los derechos

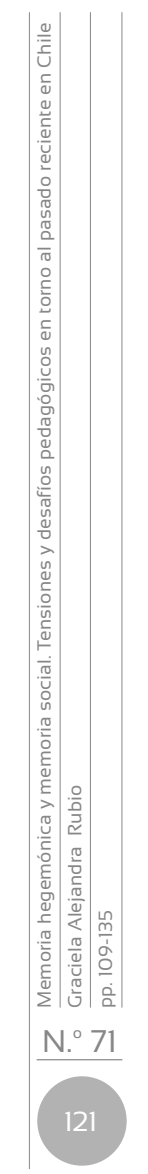


humanos, se presentan desde un enfoque cognitivo y describen solo actitudes vinculadas al presente ${ }^{33}$. Las propuestas curriculares se diferencian en el enfoque de la historia utilizado para relatar el pasado reciente, el ajuste (2009), ordena el relato desde el acontecer nacional, en el cual la Guerra Fría es contexto y causa de la crisis de la democracia y considera la memoria social como una metodología que aporta al pensamiento crítico y a la diversidad de interpretaciones históricas. En cambio, las bases curriculares del $2012^{34}$, enfatizan el marco historicista de la historia contemporánea, definiendo la historia como medio para la comprensión del presente y consideran el pasado reciente como un episodio y un efecto resultante de la Guerra Fría. No incorporan la memoria social como un referente para su análisis.

Ante los déficits de ciudadanía y la crisis de legitimidad política y democrática, el actual gobierno ha propuesto un nuevo Plan Nacional de Formación Ciudadana (2015) orientado a garantizar que todos los establecimientos educacionales reconocidos por el estado cuenten con un plan explícito que integre y complemente las definiciones curriculares para formar ciudadanos activos, responsables, participativos y comprometidos con la sociedad. Se busca generar comunidades educativas que se apropien de los recursos curriculares existentes, privilegiando contenidos asociados a la globalización, la emergencia de las sociedades del conocimiento, la sustentabilidad de la democracia en Latinoamérica y la apropiación de los sistemas de participación ciudadana ${ }^{35}$.

\section{Memorias de la sociedad civil y pasado reciente}

\section{El Museo de la memoria y de los Derechos Humanos}

El Museo de la Memoria y los Derechos Humanos inaugurado el 2010 por la Presidenta Bachelet, depende de una Fundación de derecho privado integrada por representantes del mundo académico, organizaciones de defensa y promoción de los derechos humanos y personas, en un espacio de pluralidad. Su Directorio está compuesto por académicos de universidades que cuentan con Centros de derechos humanos y por organizaciones dirigidas a su defensa y promoción en Chile. La institución se reconoce en sus orígenes como resultante de la violación de derechos humanos vivida en la Dictadura Militar, tiene como misión dar a conocer estos hechos ocurridos entre el 11 de septiembre de 1973 y el 11 de marzo de 1990 y

33 Los derechos humanos no son integrados pedagógicamente como referente del análisis histórico.

34 Elaboradas en el gobierno de derecha de Sebastián Piñera (2010-2013)

35 Entre las actividades de socialización, el Plan contempla la participación del museo de la Memoria y de los Derechos Humanos para apoyar la enseñanza del pasado reciente. 
educar y promover valores que permitan crear una sociedad más solidaria, justa y tolerante ${ }^{36}$. Se identifica como un proyecto de reparación moral a las víctimas que propone una reflexión que trascienda lo sucedido en el pasado y que sirva a las nuevas generaciones para construir un futuro mejor de respeto irrestricto a la vida y la dignidad de las personas. Contempla muestras itinerantes ${ }^{37}$ y una muestra permanente. Esta última, basada en los Informes de Verdad Rettig y Valech reconstruye la historia de violación de derechos humanos en la dictadura chilena desde el 11 de septiembre de 1973 hasta 1990. Enmarca su análisis desde las narrativas presentes en los Informes de Verdad y desde un enfoque que integra la historia política con la memoria social para dar cuenta del quiebre de la democracia ${ }^{38}$. Entre sus recursos se encuentran, fotografías, videos, testimonios, documentos, prensa y representaciones de la represión, la prisión ilegitima, la tortura, el exterminio, del movimiento por los derechos humanos, el plebiscito en la dictadura militar y el inicio de la democratización ${ }^{39}$. Sectores conservadores han cuestionado su "función pedagógica" argumentando su falta de objetividad y de integración del análisis histórico al no incluir el periodo previo al 11 de septiembre de 1973 (causa del golpe de estado y de la dictadura) y su representación democrática, al comprometerse exclusivamente con la defensa a los derechos humanos y a sus víctimas ${ }^{40}$. La potenciación de la memoria se ve favorecida por el ordenamiento narrativo y temporal que articula los derechos humanos como principios rectores del análisis con la historia politica en dictadura. La muestra permanente está dirigida a todo público, dejando abierta la subjetividad interpretativa. El área de Educación y Audiencias pretende comunicar e informar las violaciones sistemáticas a los derechos humanos entre los años 1973 y 1990 en Chile. Busca también contribuir a la reflexión, diálogo y participación

36 http://www.museodelamemoria.cl/el-museo/sobre-el-museo/fundamentos/

37 Sobre la defensa de los derechos humanos nacional e internacional, realiza múltiples actividades de discusión sobre la memoria y de la historia reciente a través del cine, el teatro y documentales.

38 Sectores conservadores de la clase política y de la historiografía han cuestionado en sus inicios (2010) y con posterioridad (2012) la existencia de un museo de la memoria financiado por el estado, entendiendo que este debía ser imparcial ante la historia.

39 Sus colecciones se organizan a través de diversos soportes y artefactos a través de los cuales se ha expresado la memoria histórica en la vida social cotidiana e internacional (Objetos, archivos documentales de memoria, archivos institucionales de administraciones del estado, publicaciones generadas en Chile o el extranjero, informes de organismos internacionales, expedientes y legajos judiciales, archivos de prensa, radial, escrita y publicaciones periódicas, archivos sonoros y fotografías, colección de entrevistas.)

40 Magdalena Krebs jefa de la Dirección de bibliotecas y Archivos en el Gobierno de Sebastián Piñera. El rechazo de sectores conservadores se ha debido, por un lado, a su defensa de la Dictadura Militar y por otro, a la necesidad de desligarse de la implicación en los daños generados por la violación de derechos humanos. En ambos casos, la causalidad (la Unidad Popular y el Caos) es el argumento para cuestionar la validez del relato del Museo. 
en la promoción para una cultura de respeto a los derechos humanos, la memoria y valores asociados a la convivencia democrática y el debate intergeneracional para lo cual desarrolla visitas guiadas y recursos para el trabajo docente. La Educación en derechos humanos y memoria, es concebida como un proceso dialógico y para toda la vida, basado en la dignidad y respeto de los derechos, de carácter plural, diversificado, participativo e inclusivo que pretende promover actitudes y comportamientos pertinentes para promover, defender y ejercer los derechos humanos en la vida cotidiana. Asume la memoria social de la violación de derechos Humanos en dictadura junto con la orientación de los derechos humanos como un recurso para la formación de capacidades ciudadanas que establece puentes para reflexionar acerca de "los imperativos éticos que nos exigen la vida democrática, la vida cotidiana y la construcción permanente de la paz. Contribuye a la construcción de memorias, sin olvido y con justicia" ${ }^{41}$. Los recursos didácticos diseñados para espacios formales y no formales y como apoyo a los contenidos curriculares, organizan la reflexión integrando la memoria social y la historia local como recursos para abordar la dictadura militar y la violación de derechos humanos. La apuesta del museo moviliza la memoria del dolor y las memorias emblemáticas del quiebre republicano y de la consistencia ética de los jóvenes de los 80 en dictadura (Stern, 2000), pudiendo desde la apuesta pedagógica, vincularlas con las memorias locales. Desde el 2015 la sección de educación atendiendo a que más del 50\% de sus visitantes son niños y jóvenes entre 10 y 19 años y atendiendo a los desafíos pedagógicos para los docentes derivados de la contextualización histórica presentada en el marco de la visita, la unidad ha elaborado una nueva propuesta de guía metodológica para la visita que contempla la discusión politica de la dictadura militar y el movimiento de defensa de los derechos humanos como procesos históricos. La propuesta introduce conceptualización política más definida para enseñar la historia reciente y apoyar el debate de memorias ${ }^{42}$.

\section{Londres 38 espacio de memorias}

Fue constituido en el año 2005 como un sitio de memoria conformado por ex detenidos sobrevivientes, familiares de detenidos desaparecidos y ejecutados, ex militantes y adherentes de izquierda sin partido. Con este sitio, se propusieron visibilizar la historia y la presencia en la ciudad del recinto de detención, tortura y exterminio que funcionó en calle Londres ${ }^{43}$.

41 http://www.museodelamemoria.cl/educacion/sobre-educacion/

42 Ver Museo de la Memoria y los Derechos Humanos. Guía temática y metodológica. Dibam2015

43 En el 2009 luego de una mesa conjunta de trabajo entre los colectivos y el gobierno, la corporación paso a Ilamarse; "Londres 38, Casa de la Memoria". 
Pretende contribuir al conocimiento y transmisión de las memorias e historia del lugar, de sus protagonistas y de las experiencias de lucha y resistencia relacionadas.

Enfatizando su origen en la experiencia de violación de derechos humanos, define su marco histórico, ético, político reconociendo el potencial de la memoria como derecho de los pueblos, el valor de su ejercicio en la conformación de capitales culturales y simbólicos en los grupos y el derecho a conocer, valorar y transmitir intergeneracionalmente las "las memorias militantes". Desde el análisis crítico de la historia, afirma que han existido diversos proyectos políticos victoriosos y derrotados ante los que se ha impuesto históricamente una "razón de estado" que ha inhibido la soberanía y participación ciudadana. Sobre los derechos humanos: rechaza explícitamente el terrorismo de estado y toda forma del estado que limite los derechos fundamentales e individuales. Reafirma la demanda irrenunciable de verdad, justicia y reparación con responsabilización. Y, la defensa de una nueva manera de hacer política, desde un concepto amplio de participación.

Asume los principios rectores de "la memoria militante" (de movimientos reivindicativos del pasado y el presente) que piensa pasado desde un presente crítico y desde una particular visión de la historia para un nuevo futuro. Ordena sus marcos interpretativos de la historia del pasado reciente desde la defensa de proyectos sociales marginados y de los derechos ciudadanos frente al estado ${ }^{44}$. Ofrece visitas auto guiadas y dialogadas junto con archivos digitales relacionados con la casa de memoria y desarrolla investigación para generar conocimiento sobre la memoria y la historia relacionada con Londres 38, contribuyendo a poner en valor las memorias sociopolíticas vinculadas al período histórico en que funcionó como centro de detención, así como a sus antecedentes y efectos en el presente. A partir de un enfoque genealógico de la historia pretende vincular a Londres 38 con: un eje teórico conceptual que relaciona la experiencia del recinto con la memoria y las luchas subalternas de América Latina, diferenciar la violencia política de la violencia terrorista aplicada sobre el movimiento popular; describir desde la investigación histórica y testimonial las dinámicas y dispositivos aplicados en el cuartel de represión ${ }^{45}$

44 Otros principios, el reconocimiento de que en el pasado chileno reciente y más remoto, así como también en el presente, han estado en juego, reiteradamente, proyectos alternativos de sociedad. Que el pasado histórico y tiempo presente se ha construido conflictivamente, como producto de nuestras diferencias, desigualdades y luchas de clases, económicas, sociales, políticas, culturales, étnicas y de género. http://www.londres38. cl/1937/w3-propertyvalue-32083.html

45 Conocido en la jerga militar como el Cuartel Yucatán, Londres38, fue el primer eslabón de una cadena de recintos de reclusión ubicados en la Región Metropolitana, que incluyó a otros tres centros clandestinos (Villa Grimaldi, José Domingo Cañas y el recinto ubicado en calle Irán $n^{\circ}$ 3037), utilizados por la Dirección de Inteligencia Nacional (Dina). 
entre 1973-1974. Por último, se propone analizar el desarrollo histórico del movimiento de memoria y de derechos humanos del cual ha formado parte Londres 38.

La "memoria militante" apuesta a la literalidad de la memoria por sobre la memoria ejemplar introduciendo una visión crítica del presente desde la experiencia del horror vivida en el recinto que extiende su relato desde 1973 hasta la actualidad. La visita guiada se inicia con una reunión en el memorial ubicado en el exterior de la casa y luego recorre su interior, con la metáfora de la casa vacía para evitar la victimización de las víctimas, organizado a partir de un único guion temático con un uso abierto y flexible, sujeto al uso discrecional del guía, de acuerdo al carácter del grupo, ordenado a través de los siguientes puntos:

-Historia de la casa: durante su uso como centro de detención, tortura y desaparición y el proyecto actual. -Contexto histórico previo y posterior. Experiencia de la Unidad Popular. -Detenidos: quiénes eran, rol de la militancia, prácticas de resistencia dentro de la casa. -Rol de la sociedad civil. -Rol de la represión en la sociedad, ver que no fue solo una experiencia de un grupo.- Efectos de la dictadura en la sociedad actual (Londres 38, espacio de memorias, 2010, pág. 7 en Bustos, 2013, 60).

Lazzara (2011) propone que Londres 38 da cuenta de una forma museológica crítica que promueve la reflexividad. Como lugar de memoria, es portador de una historicidad propia presentando una apuesta discursiva radical de la memoria y reivindicativa del pasado de los vencidos, opuesta al triunfalismo y la deshistorización promovidos por el Museo de la Memoria y los Derechos Humanos ${ }^{46}$. Por su parte, el estudio cualitativo de Isabel Pipper (2015) sobre la visita a ex sitios de prisión y tortura ha destacado, cómo estos lugares pueden transformarse en dispositivos para generar miedo en los participantes por lo que podrían no solo señalar la violencia vivida en la dictadura sino contribuir a fortalecer la cultura del miedo que ésta instaló. Lo que le lleva a reflexionar sobre cómo construir políticas de la memoria que no tengan como efecto, sujetos temerosos.

Desde nuestra perspectiva, la "memoria militante" plantea algunos desafíos pedagógicos ante las nuevas generaciones que dicen relación con la articulación entre el propósito de transmisión de memoria que asume Londres 38 y las posibilidades de reelaboración de memoria y de relación que los jóvenes visitantes pueden establecer con la historia reciente. En ello, inciden; la metáfora de la casa vacía al no potenciar el

46 La deshistorización se promueve desde la narrativa de los Informes de verdad ya abordados, junto con la ausencia de defensa politica de los sectores de izquierda en la muestra permanente. Londres38 evidenciaría la continuidad entre Dictadura y Transición. 
vínculo sensorial de los jóvenes con los hechos descritos; el sentido del énfasis de la memoria literal del horror (propia) no queda del todo articulado con el propósito de "Nunca más" (relación con memoria ejemplar) de las prácticas represivas y de exterminio; y nuevamente la presencia de un orden lineal de la narrativa histórica que está configurada de modo general la que junto con atisbos de genealogía, pueden confundir la narrativa. La continuidad de la política represiva y de violación de derechos con el presente no queda del todo argumentada para ser transferida a los jóvenes que han sido formados en el marco historicista. En cierta forma la práctica de la visita guiada, no contempla el "silencio generacional" de los jóvenes el estado de su pensamiento histórico y su relación con la historia reciente.

\section{Desafíos pedagógicos para la enseñanza de la historia reciente}

La memoria hegemónica presente en el currículum escolar evidencia una tendencia hacia la invisibilización de la memoria social para pensar el pasado reciente. La fuerza de sus marcos narrativos contribuye a naturalizar la violencia, a desresponsabilizar a la clase política y desvincular a la ciudadanía de los procesos históricos. Y muestra también, su debilidad para dialogar con los marcos ideológicos de las memorias sociales. Por su parte, el Museo de la Memoria, en su muestra permanente presenta una memoria hegemónica que reconoce parcialmente la memoria social enfatizando más, la condición de víctima que de sujeto histórico en quienes experimentaron la violación de derechos humanos. Su apuesta para dar sustentabilidad a una memoria crítica requiere de dispositivos pedagógicos que permitan cuestionar la memoria presente en el currículum escolar ${ }^{47}$. Por su parte, la apuesta radical de Londres 38 no evidencia una clara contribución a la comprensión del pasado en las nuevas generaciones herederas.

Estas condiciones en las que se mueve el recuerdo, no permiten abordar el pasado de un modo implicativo y sustentable, bloquean el diálogo y la reflexión entre la memoria social y la historia. Impiden una representación temporal colectiva y promueven una pedagogía pública del pasado reciente que desvincula la ciudadanía del estado y que consolida los marcos ideológicos y las visiones encriptadas que subyacen a las memorias transgeneracionales. Las memorias sociales requieren ser integradas junto con referencias estéticas, narrativas y éticas basadas en la democracia y los derechos humanos como principios rectores que permitan abrir el pasado reciente para pensar el futuro de una comunidad de sentido.

47 Debe evaluarse el efecto de las nuevas propuestas metodológicas. 
Visiones críticas de la modernidad, que asumen la superación de las sociedades actuales vinculando a las futuras generaciones en procesos participativos y activos en su presente complejo, han propuesto para una relación entre memoria e historia en educación; la "Razón anamnética" (Metz, 1993, en Cuesta,2011) y la "Competencia histórica" (Beanvot A. y Braslavsky, C.2008), desplazando la discusión desde la verdad, hacia la praxis con sentido político para formar una ciudadanía responsable de su pasado y su futuro, sustentada en; el "derecho a tener derechos", como una condición en permanente expansión (Arendt, 1973; Lechner, 1986 et al, en Jelin, 2003 ) en donde el pasado se transforma en un recurso para la confrontación del presente y el futuro, en el cual, la memoria agencia procesos de subjetivación y política. La didáctica critica (Cuesta, 2011) sustentada en historia con memoria, entiende la memoria como un método crítico político que valida el recuerdo como acto de pensar y entender el mundo. A partir del pensar rememorante, que rescata el pasado ignorado de los vencidos como objeto de confrontación dialéctica con el presente, recordar implica una búsqueda y un despertar que abre procesos hermenéuticos en quien recuerda. El pasado convertido en texto, no posee un argumento preestablecido y "[...] requiere un cepillado a contrapelo que permita hacer emerger el relato del pasado ausente en las narrativas oficiales de la historia" (Cuesta, 2011, p.19). Desde esta visión, las memorias sociales se sitúan en un campo de fuerzas, "la economía política del recuerdo" y corresponde a la educación desde una historia crítica de su presente, promover una "historia con memoria", con un valor genuinamente educativo (Melich, $2004)^{48}$. La didáctica crítica basada en "la historia con memoria", es una actividad teórico práctica de la educación, que actúa en las relaciones de saber/poder en la esfera pública de las políticas de la cultura y puede contribuir a; "[...] modificar las asimetrías de poder que reinan en los espacios públicos de la vida democrática" (Cuesta, 2011, p. 21). Por lo cual: "[...] una didáctica crítica se fundamenta en la problematización del presente y pensar históricamente el pasado, exige acudir a la memoria (historia con memoria) y a su uso público con vistas al ejercicio pleno de la ciudadanía" (Cuesta, 2011, p. 21) ${ }^{49}$. La finalidad educativa no se resuelve en la llegada a un consenso, más aun, cuando una sociedad está dividida o segmentada es imposible suponer desde esta perspectiva, una memoria compartida.

El carácter selectivo del recuerdo y el olvido, insta a atender qué recordar y relevar del pasado. La necesidad de memoria en estos contextos,

48 Ética sustentada en el imperativo categórico de Adorno (que Auschwitz no se repita), para educar contra la barbarie.

49 La problematización del presente puede realizarse desde un fenómeno social contingente que exige su genealogía o, frente un pasado como el dictatorial chileno que prescribe un recorrido específico de acuerdo a los hechos que en el presente demandan su pasado para la comprensión. 
se sustenta en un fortalecimiento de los vínculos humanos en donde esta deviene en instrumento de vida. Bárcena (2011), propone una Pedagogía de la memoria para fortalecer la generación de una comunidad de sentido que articule un vínculo con el pasado, visión que se distancia del pasado historicista (usado como causa explicativa del presente) y de la visión moralista de la memoria (exacerbar la condición de víctima y asesino). La pedagogía de la memoria propuesta, debe promover la comprensión y atribución de sentido, el cual no reside en el hecho, sino en el sujeto y en su capacidad de elaborar un juicio político como un modo de asumir los pasados de dolor. El proyecto educativo de enseñar a través del recuerdo debe romper las condiciones que han enmarcado lo indecidible de ese pasado: "una cosa es lo indecible de un acontecimiento como experiencia vivida por un testigo/un superviviente de un campo de concentración y otra muy distinta, lo indecible como dogma impuesto por un discurso externo a la experiencia vivida" (Didi Huberman,2004 en Bárcena,2011, p.112-113). Se debe evitar "la pedagogización del recuerdo", transformarlo en un ritual repetitivo de acercamiento al pasado que prescribe hechos que se deben recordar. Esto implica esquivar las fuerzas que imponen la transmisión educativa de una memoria ya significada por un deber de memoria que impide su auténtico trabajo. El deber de memoria reside primordialmente en los herederos, quienes son los Ilamados a ejercer la memoria en los campos de poder, promoviendo una vigilancia sobre el recuerdo, actualizando e imaginando en el presente lo que debería asemejarse al pasado y recordando el pasado como un presente. Una memoria ejemplar no estará al servicio del hecho, sino que contribuye a la mejora de las relaciones actuales con otros, en una relación de contemporaneidad, de comprensión posible, de un tiempo del cual formamos parte. Implica también, un espacio de lucha contra el olvido y una apertura a las otras memorias que pugnan por entrar en la deliberación pública ${ }^{50}$. Un especial cuidado requiere la transmisión de una memoria de lo no vivido proveniente de una experiencia concentracionaria. En esta pedagogía, el testimonio es un tipo de conocimiento portador de una sabiduría imposible, pero necesaria. En su lectura confluyen la experiencia de realidad sufrida y la transmisión del dolor. Su negación,

forma parte de los efectos destructores del crimen, y de ahí la necesidad, tanto de profundizar en esta noción, como de considerar hasta qué punto la sacralización social de los escritos de los testigos de experiencias concentracionarias tiene efectos perversos cuando se reproduce como una especie de reciclaje comercial (Bárcena, 2011, p.115).

De acuerdo a lo anterior, una pedagogía de la memoria debe basarse en un diálogo crítico entre Memoria e Historia para el futuro de una

50 Esto supone la defensa del derecho a la verdad y la memoria. 
ciudadanía memorial y que la propuesta para sustentar la enseñanza del pasado reciente en Chile debe integrar bases hermenéuticas y críticas para la formación ciudadana y validar el potencial crítico del diálogo entre memoria e historia para la comprensión del Pasado Reciente dictatorial $^{51}$. Los que se pueden expresar en los siguientes principios de la acción pedagógica; comprender la historia a partir de los efectos de la historia reciente. Esto orienta qué y cómo recordar. El pasado reciente ha generado efectos diferenciados en nuestra sociedad expresada como; víctimas, allegados, herederos, colaboradores, "cómplices pasivos" y comunidades de sentido futuras. Deben considerarse en relación a la definición de los hechos históricos que pretendemos relevar para articular la relación entre memoria e historia y potenciar la comprensión histórica.

Considerar las determinaciones de posición económica y social frente al pasado reciente. Cada trayectoria del pasado inscribe una determinación de posición histórica (Giroux, 2003) que incide en la narrativa del recuerdo sobre el pasado que se expresa a través de las memorias emblemáticas y sociales. Las determinaciones aportan a la comprensión de experiencias disímiles heredadas para iniciar el trabajo de la memoria.

Reconocer la enseñanza como un espacio para la creación de una comunidad de sentido. La enseñanza del recuerdo debe orientarse pensando en el futuro y en la formación ciudadana (Bárcena, 2011). Ello define el compromiso explícito de esta enseñanza para la formación de ciudadanos responsables que sustentan sus análisis históricos en los derechos humanos.

Y reconocer que es posible definir algunos ejes de enseñanza prioritarios de reflexión. Desde nuestra experiencia de la política de campo sustentada en la pedagogía pública del miedo (Rubio,2013a) instaurada desde el estado, emergen algunos ejes de enseñanza prioritarios tales como; El quiebre de la vida republicana que demanda pproblematizar el tiempo, cuestionar las herencias y las posibilidades fácticas de construcción de la institucionalidad republicana; superar la linealidad y continuidad como ordenadores del relato histórico, tensionando la narración encadenada de los hechos establecidos como verdad y abrir ese pasado.

El daño y dolor del cuerpo y La ciudadanía vulnerada; demandan, aprender la convivencia política como el cuidado del otro y problematizar la experiencia heredada desde la responsabilidad ante el futuro.

51 La crítica supone debatir sobre los principios que han ordenado la investigación histórica y su rol en la elaboración del pasado reciente. Abrir dialogo desde el presente hacia el pasado activando, memoria e historia. 


\section{Referencias bibliográficas}

Aróstegui, J. (2006). Memoria y revisionismo. El caso de los conflictos españoles del siglo xx. Cuadernos de Pedagogía (362), 54-58.

Bárcena, F. (2011). Pedagogía de la memoria y transmisión del mundo. Notas para una reflexión. Revista Con-Ciencia Social, (15), pp. 109118.

Beanvot, A. y Braslavsky, C. (2008). El conocimiento escolar en una perspectiva histórica comparativa. Cambio de currículos en la educación primaria y secundaria. Francia-Buenos Aires. Comparative Education research Centre (CERC) UNESCO. Instituto Internacional para la Planificación Educativa (IIEP).

Brett, S. et al. (2007). Memorialización y Democracia. Políticas de Estado y Acción Civil. Recuperado de: http://issuu.com/flacso.chile/docs/ memorializationspanishv5

Bustos, X. (2013). La memoria de los jóvenes. Discurso transmitido y reelaboracion de la memoria en una experiencia guiada en Londres 38. El caso de los estudiantes de tercero medio del colegio Regina Pacis. (Tesis de pregrado). Santiago, Universidad Academia de Humanismo Cristiano.

Carvacho, H. y Manzi, J. et al.(2013). Identidad Social y Emociones Intergrupales: Antecedentes de las Actitudes de Perdón y Reparación Política en Chile. PSYKHE, 22, (2), 129-146.

Carvacho, H. et al. (2013). Consenso y Disenso en la Memoria Histórica y en las Actitudes Hacia la Reparación en Tres Generaciones de Chilenos. Pontificia Universidad Católica de Chile. PSYKHE, Vol. 22, (2), $33-47$.

CEPAL. (2007). Cohesión social. Inclusión y sentido de pertenencia. Santiago.

Collins, C. y Hite, K. (2013). Fragmentos de memoriales, silencios monumentales y despertares en el Chile del siglo xxı. En Collins, K. y Joignant, A. Las políticas de la memoria en Chile: Desde Pinochet a Bachelet. (pp. 161-192). Santiago: Ediciones Universidad Diego Portales.

Comisión Nacional de Verdad y Reconciliación. (1991). Informe Comisión Nacional de Verdad y Reconciliación (Rettig). Santiago: Corporación Nacional de Reparación y Reconciliación.

Comisión Nacional sobre Prisión Política y Tortura. (2004). Informe Comisión Nacional sobre Prisión Política y Tortura (Valech). Santiago: Gobierno de Chile, Ministerio del Interior.

Cuesta, R. (2015.) La venganza de la memoria y las paradojas de la historia (s. e. d). 
Cuesta, R. (2011). Historia con memoria. Revista Con-Ciencia Social, (15), pp. 15-30.

Elster, J. (2006). Rendición de cuentas. La justicia transicional en perspectiva histórica. Buenos Aires. Katz Editores.

Faúndez, X., Cornejo, M. y Brackelaire, J. C. (2013). Transgeneracionalidad del Trauma Psicosocial: Imágenes de la Detención de Presos Políticos de la Dictadura Militar Chilena Reconstruidas por los Nietos. PSYKHE, 22, (2), 83-95 doi:10.7764/psykhe.22.2.563

Garretón, M. A. (2003). Memoria y Proyecto País. Revista de Ciencia Política, xxIII, (2), pp. 215-230. Recuperado de: http://www.scielo.cl/pdf/ revcipol/v23n2/art10.pdf

Garretón, M. F. et al. (2011). Políticas públicas de verdad en siete países de América Latina. Santiago. Facultad de Derecho Universidad de Chile. Recuperado de: http://www.cdh.uchile.cl/media/publicaciones/pdf/78.pdf

Giroux, H. (2003). Pedagogía y política de la esperanza. Buenos Aires. Amorroutu.

PNUD. (2015). Los tiempos de la politización. Recuperado de: http:// desarrollohumano.cl/idh/informes/2015-los-tiempos-de-la-politizacion/

PNUD y Unicef. (2014). El papel de la educación en la formación del bienestar subjetivo para el desarrollo humano. Una revisión del caso chileno. Recuperado de: http://desarrollohumano.cl/idh/download/Educacion-y-bienestar-subjetivo2.pdf

PNUD (2002). Nosotros los chilenos. Un desafío cultural. Recuperado de: http://desarrollohumano.cl/idh/download/2002.pdf

Jaramillo, J. (2009, enero-diciembre). Tres experiencias emblemáticas de recuperación de pasados violentos en América Latina. Argentina, Guatemala y Colombia. Antropo.sociol. (11), pp. 29-59. Recuperado de: http://virajes.ucaldas.edu.co/downloads/Virajes11_2.pdf

Jelin, E. (2003). Los derechos humanos y la memoria de la violencia política y la represión: la construcción de un campo nuevo en las ciencias sociales. Cuadernos del IDES.

Jelin, E. (2002). Los trabajos de la memoria. Memorias de la represión. Madrid: Siglo Xxı Editores.

Lazzara, M. (2011). Dos propuestas de conmemoración pública: Londres 38 y Museo de la Memoria y de los Derechos Humanos. A contracorriente. 8 (3), pp. 55-90. Recuperado de: www.ncsu/proyect/ aconttracorriente

Lechner, N. (2006). Obras escogidas. (Colección Pensadores Latinoamericanos). Santiago: LOM Ediciones. 
Lechner, N. (2007). Obras escogidas. (Colección Pensadores Latinoamericanos). Santiago: Lom Ediciones.

Lechner, N. (1999). Desafíos de un desarrollo humano: Individualización y capital social. París: Asamblea General del Banco Interamericano de Desarrollo (BID). Recuperado de: www.desarrollohumano.clextencio/bid.pdf

Lechner, N. y Guell, P. (2006). La construcción social de las memorias en la transición chilena. En Jelin E. y Kaufman S. (Comps). Subjetividad y figuras de la memoria. Memorias de la Represión. pp. 17-46. Argentina: Siglo xxI.

Lefranc, S. (2003). Aquello que se conmemora. ¿Democracias sin un pasado compartido? Scielo. Revista de ciencia política. Santiago. Recuperado de: http://www.scielo.cl/pdf/revcipol/v23n2/art11.pdf

Lefranc, S. (2004). Políticas del perdón. Bogotá: Grupo Norma

Hunneus, C. e Ibarra, S. (2013). La memoria del régimen de Pinochet desde la opinión pública. En Collins, K.; Joignant, A. Las políticas de la memoria en Chile: Desde Pinochet a Bachelet (pp. 227-264). Santiago: Ediciones Universidad Diego Portales.

Melich, J. C. (2004). La lección de Auschwitz. Barcelona. Herder.

Ministerio de Educación Nacional. (2013). Orientaciones técnicas y Guiones didácticos para fortalecer la formación ciudadana. De 7 a 4 medio. Asignatura Historia y Ciencias Sociales.

Ministerio de Educación Nacional. (2010). Estudio Internacional de educación cívica y formación ciudadana.

Ministerio de Educación Nacional. (2011). Estándares orientadores para los egresados de las carreras de pedagogía en educación básica.

Ministerio de Educación Nacional. (2011). Estándares pedagógicos y disciplinarios.

Ministerio de Educación Nacional. (1998). Marco curricular. Santiago.

Mudrovic, M. E. (2005). Historia, narración y memoria. Los debates actuales en filosofía de la Historia. Madrid: Akal.

Museo de la Memoria y de los Derechos Humanos. (2015). Guía temática y metodológica. Santiago.

Opción-ECEN. Los ruidos del silencio. Los niños, niñas y adolescentes hablan a cuarenta años del golpe militar en Chile. Santiago. Recuperado de: http://www.opcion.cl/

Osorio, y Rubio, G. (2014). Pedagogía de la Memoria i Ciutadania Democratica: tesis per a la deliberació. Quaders d'Educació Contínua, Nº. 30, Valencia. Recuperado de: htpp://www.dge.uem.br

Osorio, y Rubio, G. (2006). El Deseo de la Memoria. Escritura e Historia. Santiago: Escuela de Humanidades y Política. 
Pipper, I. (2015). Violencia politica. Miedo y amenaza en lugares de memoria. Athenea Digital, 15, (4), pp. 155-172. Recuperado de: http:// atheneadigital.net/article/view/v15-n4-piper

Pollak, M. (2006). Memoria, olvido y silencio. La producción social de identidades frente a situaciones límite. La Plata: Ediciones Al Margen.

Reyes, L. (2004). Actores, conflicto y memoria: reforma curricular de historia y ciencias sociales en Chile, 1990-2003. En Jelin, E. y Lorenz, F. (Comp.). Educación y Memoria: La escuela elabora el pasado. pp. 65-93. Buenos Aires: Siglo XXI.

Reyes Mate (2008). La herencia del olvido. Madrid: Editorial Errata naturae.

Ricoeur, P. (2004). La Historia la memoria y el olvido. Buenos Aires: Fondo de Cultura Económica.

Rubio, G. (2014). Memoria histórica, ciudadanía y crisis moral de la esfera pública. Chile a 40 años del golpe militar de 1973. Revista Clivajes, (2). Recuperado de: http://revistas.uv.mx/index.php/Clivajes

Rubio, G. (2013a). Memoria política y pedagogía. Los caminos hacia la enseñanza del pasado reciente. Santiago: Lom Ediciones.

Rubio, G. (2013b). Memoria, ciudadanía y lo público en la elaboración del pasado reciente en la experiencia chilena. Memoria y Sociedad. Pontificia Universidad Javeriana. Recuperado de: http://www.scielo. org.co/revistas/meso/eaboutj.htm

Ruiz Torres, P. (2007). Los discursos de la memoria histórica en España. Hispania Nova. Revista de Historia Contemporánea, (7), 5-30.

Salazar y Grez, S. (1999). Manifiesto de los historiadores. Santiago: LOM Editores.

Stern, E. (2000). De la memoria suelta a la memoria emblemática: Hacia el recordar y el olvidar como proceso histórico. Chile (19731998). En Garcés, M. et al (Comp.). Memorias para un nuevo siglo. Chile. Miradas a la segunda mitad del siglo xx. Santiago: Lom Ediciones-Eco.

Stern, E. (2013). La ironía de la política de la memoria post-heroica: Chile y la cultura mundial. En Collins, K. y Joignant, A. Las políticas de la memoria en Chile: Desde Pinochet a Bachelet. pp. 9-23. Santiago: Ediciones Universidad Diego Portales.

Todorov, Z. (2000). Los abusos de la memoria. Barcelona: Paidós.

Vélez, G. y Herrera, M. C. (2014 ). Formación politica en el tiempo presente. Ecologías violentas y pedagogía de la memoria. Nómadas (41). Universidad Central Colombia. Recuperado de: https://www.ucentral.edu.co/images/editorial/nomadas/docs/41-9-formacion-politica-en-el-tiempo-presente.pdf 149-165 
Wilde, A. (2013). Un tiempo de memoria. Los derechos humanos en la larga transición chilena. En Collins, K. y Joignant, A. Las políticas de la memoria en Chile: Desde Pinochet a Bachelet. pp. 55-84. Santiago: Ediciones Universidad Diego Portales. 